\title{
NEGATION AFFIXES IN ENGLISH
}

\section{Dedy Subandowo}

\author{
Muhammadiyah University of Metro
}

\begin{abstract}
This research entitled "Negation Affixes in English". This study is aimed to describe the various negation affixes in English, morphological process, morphophonemic and meaning. The research data were taken from various sources of English grammar book, morphology, research journal and the book which relatees to the research. English grammar books used in this study are written by Otto Jesperson, Marcella Frank, Greenbaum and Geoffrey Leech. The method used in this research is the descriptive-qualitative method. While the data collection techniques are performed by using jot-down method. And the results of analysis are presented in tabular form and descriptive method. The result of the research shows that English has six types of negative affixes which are categorized by the intensity of its appearance, such as dis-, in-, non-, un-, anti- and -less. Based on the function, negation affixes are divided into several categories such as adjectives, nouns, verbs, and adverbs. The morphophonemic affix in- has four allomorphs, they are in-, im-, iland $i r$ - . While the analysis revealed that negation affixes have some basic meanings, such as 'not', 'without', and 'anti'.
\end{abstract}

Keyword: Negative Affixes, English, Morphology

\section{Introduction}

Negation is not a new topic

which accured recently. It has been

argued since Aristotle came out with

the idea about logic. Aristotle clearly

attaches the greatest importance to this topic. He sets out three types of opposition of particular interest such as contrariety, privation, and contradiction. Aristotle says that contradiction is the primary opposition, for it is sheer, 
unintermediated opposition. But it is and this may be crucial an opposition of statements, not of terms (and so, of things). To be sure, the asserted propositions are indeed also about things. But Aristotle insists:

"...what underlies the affirmation and negation is not the affirmation or negation for what underlies is in no way a sentence. These things are, however, said to oppose each other as do affirmation and negation". (EvaT.H. Brann The way of Naysaying in http://books.google.co.id/books /the_way_of_naysaying)

Negation is the act or an instance of denying (Rakhmania, 2009:1). It is the opposite of a positive character or quality. Almost as soon as we are born, we can use negation indicated by gesture or other behaviors that we reject, exclude or disagree with something. Because it is so common and easily-mastered, negation may seem to be a simple concept. However, the use of negation in our daily lives is not as simple as it seems. Like stated above, negation may be indicated by gesture and other behaviors, such as, utterance. By gesture, we can show negation by shaking our head by moving it side to side. But it is not always the case. In other country with different cultures, there are a lot of ways to show negation. Another way of negating is through the utterance. As we all know, in grammar, negation is the process to transform an affirmative statement into its opposite (negative statement).

We often use a single word ' $n o$ ' to say that we do not have the same idea as what has been said or asked. We use 'not' also to state 
disagreement but it does not stand alone, as in He is not running or He is not intelligent these come after a be and followed by verb (running) or adjective (intelligent) etc.

Affixal negation is a process of word-formation, by which a new word is built from a word stem, usually through the addition of an affix, either at the beginning (prefix) or the end of the stem (suffix). A negative affix is an affix that opposes or negates a word (Dzuganova, 2006:332). The word disagree also denotes negation because it is the opposite of the word agree a positive idea which then be added by a prefix dis-, indicating negative idea.

\section{Discussion}

The most frequently used negative prefixes are: dis-, in-, non-, un- and anti-. There is only one negative suffix -less (Dzuganova, 2006:332)

1. Negative Prefix dis-

Jespersen (1960) writes:

"the prefix dis- (from Latin) besides various other meanings also has that of a pure negative, as in dissimilar, dishonest, disagree, disuse, dislike, disbelieve, generally implying contrary rather than contradictory opposition." The negative prefix dis- is used most often with verbs and abstract nouns, as in the following examples: disobey - disobedience, disbelieve- disbelief, displease displeasure. Dis- added to adjectives makes them negative, e.g. dishonest, disloyal, and disobedient. 
2. Negative Prefix in-

The negative prefix inadded to adjectives means "not" (incompatible, incompetent, independent, inorganic, insufficient, intolerant, invalid); and added to nouns means "without, lacking" (inaccuracy, inattention, incompatibility, incompetence, innutrition, insufficiency, intolerance). We have not found any verb negated by means of in-.

According to the rules of Latin phonology the prefix in- can have four basic forms (called allomorphs), e.g. indecent, impossible, illogical, irrational according to the beginning consonant of the word to which it is added. Before the consonants /b/, $/ \mathrm{m} /$, and $/ \mathrm{p} /$, in- becomes im-: imbalanced, immature, immediate, immedicable, impatient, before words starting with the letter "1", in- changes into il- as in illegal, illegible, illegitimate, illogical. The allomorphic ir- variety can be added to some words beginning with the consonant "r", e.g. irrational, irregular, ir- relevant, irreligious, irresponsible. (The Oxford Encyclopedic English Dictionary).

\section{Negative Prefix non-}

The prefix non-, which means "not", comes from Latin non. The prefix was used primarily in Roman law terms, which were adopted into Old French and then into English. Non- can be added to almost any adjective. Some examples include non-active, non- 
breakable, non-defensive, nonspecific, nonessential, noninterrupted, non-irritating, and non-productive. Non- also combines with many nouns, as in nonentity, nonresident, and nonviolence. It never combines with verbs.

It is interesting to note that the great majority of non-formed adjectives are morphologically complex words. Most of them end in -al, -ible, -ic, -ing, -ous, etc. This may be connected with the fact that many simplex adjectives (such as small, long) have obvious simplex antonyms.

The spelling of the prefix non-varies. In the older texts, dictionaries, textbooks, and other materials the prefix non- was strictly written with hyphen, today it is more and more written together with word it negates (very frequent in American English), or both varieties are used (dzuganova, 2006:334).

According to Randolph Quirk et al (1985) the negative prefix non- means "not" or "absence of something" and can be used with adjectives, adverbs and nouns, e.g. non-academic, non-economic, nonessential, non-existent, nonalcoholic, non-fatal; nonsmoker, non-reader; non-essentially. It is also used to form a neutral negative sense when a form in inor un- has a special sense or usually unfavourable connotation e.g. noncontroversial vs uncontroversial; non-effectivex 
ineffective; nonhuman $\mathrm{x}$ unhuman

$\mathrm{x}$ inhuman.

4. Negative Prefix un-

"Un-" is the native English

prefix used for negation. The negative prefix un- chiefly attaches

to simple adjectives with a native basis, e.g. unclean, uneven, unfair, unwise, unafraid, unfit. Many derived adjectives also take this prefix. Denominal derivatives are chiefly characterized by the suffixes -ed, -y, -ly, -ful, -al, -ish, (i)ous, -worthy. Examples are: unprincipled, unlucky, unmotherly, unfaithful, unconditional, unselfish, unceremonious, and untrustworthy. Deverbal derivatives are likewise common. They are all formed with the suffix -able. Some examples of this very productive type are unbelievable, unacceptable, unachievable, unadvisable, etc.

It also attaches to adjectives made of participles, as in $u n$ bending, unending, unfailing, unfeeling, etc.; unborn, unemployed, unfinished, unseen, unstressed, untouched, unsaid etc. Less frequently, this same prefix attaches to nouns: unacceptance, unbelief, unconcern, unharmony, unhealth, unheroism, unintelligence, uninterruption, unluck, unsuccess, unsatisfaction, unrest, etc.

Some words that take the un- prefix in their adjectival form may have a noun form that uses the negative prefix in-. Such combinations include: unable vs 
inability, uncivil (ill-mannered,

rude) vs incivility (lack of politeness), unequal vs inequality, unjust vs injustice, unstable vs instability.

5. Negative Prefix Anti-

Negative prefiks anti- is derived from the Greek which is used to denote the opposite of something. In general, antiattached to nouns and adjectives, such as antisubmarine "against the submarines", anti-aircraft 'describes weapons, equipment or activities that are intended to destroy or defend against enemy aircraft', anti-terrorist, antisocial, anti-clockwise "direction opposite clockwise", and antifreeze.
6. Negative Suffix -less

The only negative suffix in English is the suffix -less. It comes from the Old English word leas, meaning "without". In Old English and Middle English, -less was often used to convey the negative or opposite of words ending in -ful, as in careful - careless, colourful colourless, doubtful —doubtless, fearful —fearless, fruitful — fruitless, helpful - helpless, hopeful hopeless, meaningful - meaningless, useful-useless.

\section{Conclusion}

There are six affixes as negation markers in English; dis-, in-, 
non-, un-, anti-, and-less. There are

only two afixes that categorized into native English; un- and-less. Affixes dis- (Latin) found in adjectives, verbs and abstract nouns. The prefix dis- has a negative meaning (pure negative) such as 'against', 'lack of something or 'not'. Prefix dis- is generally more reflective the opposite forms than contradictory forms.

Negation prefix in- is specially attached to an adjective beginning with the sounds / b/, /1/, /m/, /p/, or $/ \mathrm{t} /$. Prefix in- comes from Latin. Prefix inis essentially has basic meaning "not". Based on the rules of Latin phonology, prefix in- has four forms, in-, im-, il-, and ir-. Affix in- chnges into imbefore consonant / b /, /m/ and /p /, before words starting with the letter ' $l$ ', in- changes into il-. The allomorphic $i r$ - variety can be added to some words beginning with the consonants /r/. Prefix in- has various meanings such as, not, opposite of , without and lacking.

Prefix non- is from Latin. Prefix non- is attached to adjectives ending -al, -ible, -ic, -ing, -ous, adverbs and nouns. The prefix un- is attached to adjectives and nouns, and can be attached to verbs and nouns to form verbs. Prefix non- has basic meaning "not" and "without". The spelling of the prefix non- which appears in the older texts, dictionaries, textbooks, and other materials was strictly written with hypen, today it more and more written together with word it negates (very frequent in American English), or both varieties are used. It means that Frence non- of Latin origin is not felt foreign in 
English any more and it is being anglicitized.

The prefix $u n$ - is native English which is used for negation. In Old English prefix $u n$ - has a role very productive, especially in the adjective. Prefix un- has basic meaning "not". The negative prefix un- chiefly attaches to simple adjectives with a native basis. Many derived adjectives also take this prefix. The denominal derivative are chiefly characterized by the suffixes -ed, -y, -ly, -ful, -al, -ish, (i)ous, -worthy. Deverbal derivatives are likewise common. They are all formed with the suffix -able. Prefix un- is also attached to adjectives made of participles.

Prefix anti- is originally from Greek. This prefix has basic meaning "opposed to; against". In general, this negative prefix anti- is attcahed to nouns and adjectives. The only negative suffix in English is -less. This suffix has basic meaning "without". This suffix is to convey the negative or opposite of words ending in $-f u l$.

\section{References}

Dzuganova. 2006. "Negative Affixes in Medical English". Foreign Language Department Jessenius faculty of Medicine, Comenius University, Martin, Slovakia.

Greenbaum, Sidney \& Randolph Quirk.1973. A University Grammar of English. London: Longman Group Limited. 
Jesperson, Otto. 1971. Negation in Englsih and Other Languages.

A.F. Host.

Quirk et al. A Comprehensive Grammar of the English Language. Longman 1985, 1540-1541.
Rakhmania, Ria. 2009. “A comparison between English and Indonesian negation marker”. Jakarta: Universitas Gunadarma.

The 0xford Encyclopedic English Dictionary. Oxford, University Press 1991. 